Universidad de Guadalajara

Derecho Global. Estudios sobre Derecho y Justicia

Año 3, núm 9, julio-octubre, 2018, pp.57-80, ISSN: 2448-5128 e-ISSN: 2448-5136

https://doi.org/10.32870/dgedj.v0i9.166

\title{
Consentimiento informado en la prestación de servicios de salud
}

\section{Informed consent in the provision of health services}

Recibido: 22/12/2017

\author{
Claudia Patricia Orellana Robalino
}

Aceptado: 07/03/2018

\author{
Abogada Universidad Andina Simón Bolívar, Ecuador
}

claudia.orellana@sedesde.com

RESUMEN: El presente ensayo es de tipo explicativo, descriptivo y argumentativo cuyo objeto principal es evidenciar la importancia del consentimiento informado, que actúa como garantía para el ejercicio del derecho a la salud. Los métodos utilizados son el exegético para demostrar y comprender la importancia del principio de autonomía y su principio derivado del consentimiento informado en el ordenamiento jurídico y en lo específico en la relación médico paciente. Así mismo se utiliza el método de derecho comparado y de análisis del caso para examinar dos sentencias una de la Corte IDH y otro del TEDH con el objetivo de evidenciar como en la realidad material o práctica se desnaturaliza y descontextualiza el consentimiento informado de los pacientes violentando sus derechos.

PALABRAS CLAVE: principio de autonomía, consentimiento informado, derecho a la salud, bioderecho, contrato, servicios de salud.

\begin{abstract}
This essay is clarifying, descriptive and argumentative, whose main objective is to demonstrate the importance of informed consent, which acts as a guarantee for the deployment of the right to health. The essay methodologies are: exegetical to demonstrate and understand the importance of the principle of autonomy and the informed consent principle in the legal system, and in the doctor- patient relationship. It also uses the comparative and the case brief method to examine two resolutions: one of the InterAmerican human rights Court and another of the ECHR, to show that the Informent consent in the daily practice can be decontextualized violating human rights.
\end{abstract}

KEY WORDS: autonomy principle, informed consent, right to health, biolaw, contract, health services. 


\section{SUMARIO}

Introducción. I. Principio de autonomía como fundamento del consentimiento informado. I.1 Evolución histórica del principio de autonomía. I.2 Principio de autonomía privada como el origen de la relación contractual médico paciente. I.3 Principio de autonomía privada en el ámbito del bioderecho y su influencia en la relación médico paciente. II. Análisis del contenido del consentimiento informado en el contrato de prestación de servicios de salud. II.1 Análisis del consentimiento informado desde el ámbito contractual, requisitos y características. II.2 Principio de consentimiento informado en el bioderecho. III. Consentimiento informado garantía del ejercicio del derecho a la salud III.1 Regional: Caso Ximenes Lopes vs. Brasil sentencia de la Corte IDH. III.2 Internacional: Caso Evans vs. Reuno Unido del Tribunal Europeo. IV. Conclusiones. Bibliografía.

\section{Introducción}

El ensayo está compuesto de tres argumentos que son: (1) El principio de autonomía como fundamento del consentimiento informado, inicia con el análisis histórico del principio de autonomía para evidenciar su inclusión a lo largo de la historia en diferentes materias del derecho, y se analiza la adaptación del principio de autonomía en dos materias del derecho: (i) en contratos, que concibe al principio de autonomía como la libertad contractual que se expresa a través del negocio o acto jurídico. (ii) Principio de autonomía como principio básico del bioderecho que exige el respeto de la capacidad de auto determinarse de las personas. (2) En el segundo argumento, se analiza el contenido mínimo del consentimiento informado, sus requisitos y características principales desde el ámbito contractual. A su vez se analiza el consentimiento informado desde el ámbito del bioderecho. (3) En el último argumento se analizan dos casos: Evans vs. Reino Unido sentencia del TEDH de 2006 y el caso Ximenes Lopes vs. Brasil sentencia de la CorteIDH de 2006, con el objetivo de evidenciar la importancia del consentimiento informado como garantía del derecho a la salud, sea que se ejerza de forma positiva al aceptar el tratamiento o de manera negativa 
al revocarlo, todo esto partiendo del concepto del derecho a la salud como la libertad de decidir sobre la salud propia y el acceso a servicios de salud bajo parámetros mínimos como accesibilidad, adaptabilidad, calidad y disponibilidad.

\section{Principio de autonomía como fundamento del consentimiento informado}

El principio de autonomía es reconocido como parte de los principios generales del derecho, cuya característica principal es ser "ius cogens", es aplicado tanto en el ámbito público y como en el privado y se relaciona con el concepto de orden público, que dependiendo de su concepción es limitante, en menor o mayor grado, del principio de autonomía. Como antecedente se mencionará un breve resumen de la historia del principio de autonomía con el objetivo de demostrar su ampliación y aplicación en diferentes ramas del derecho.

Se hace énfasis en las perspectivas de dos ramas del derecho: 1) Contratos: el principio de autonomía es fundamental para la existencia del negocio y acto jurídico, y 2) En el bioderecho como principio bioético básico aplicable a los servicios de salud, tratamientos médicos e investigación científica con seres humanos.

Entonces se demuestra una interrelación de la concepción del principio de autonomía en el ámbito contractual y del bioderecho, porque la relación médico paciente es de ámbito contractual, pues el paciente tiene la autonomía de aceptar o no los términos y condiciones de una intervención médica, siendo de vital importancia la libertad o autonomía de cada paciente al momento de decidir sobre su salud.

Es así como el principio de autonomía sea desde el enfoque contractual o del bioderecho promueven el ejercicio del derecho a la libertad personal para tomar decisiones conscientes, libres e informadas sobre nuestra salud.

\footnotetext{
1 La característica de "ius cogens" o "jus cogens" es una expresión en latín o locución latina, que expresa el carácter imperativo de los derechos humanos, que son parte de los principios generales del derecho. Monroy Cabra, 2008, p. 150 cita de Monroy Cabra, Derechos de los tratados, $2^{\text {a }}$ ed. Bogotá, Edit. Leyer, 1995, p. 132.
} 


\section{1 Evolución histórica del principio de autonomía}

El jurista Monroy Cabra señala que el principio de autonomía privada se ha reconocido en el Derecho a lo largo de las etapas históricas de la humanidad. Desde la edad antigua en el Derecho Romano clásico se reconoció la "voluntatis" o voluntad de la persona al momento de contratar, sin embargo, para los juristas romanos de la época no es suficiente la voluntad humana para que genere efectos jurídicos, ya que la voluntad se somete a las leyes vigentes. ${ }^{2}$ Durante la edad media el principio de autonomía es reconocido en menor grado, debido a que:

"La concepción formalista del contrato implicaba una interpretación literal-formal, sin ninguna consideración a los motivos determinantes del acto o contrato. Lo anterior permite concluir que en el derecho medieval se advierte la insuficiencia del mero consentimiento para originar una obligación” (Monroy Cabra, Introducción al Derecho, 2008, p.51)

Es a partir de la alta edad media que el principio de autonomía adquiere mayor importancia en el ámbito del comercio, debido a que en los contratos comerciales la libertad contractual es básica para determinar el objeto del contrato, las obligaciones y efecto legales. Más tarde en la edad moderna las obras de juristas como Domat, Porthier y Grocio, entre otros, contribuyen a que el principio de autonomía sea la libertad del hombre de disponer de sus propios actos. (Monroy Cabra, Introducción al Derecho 2008, p.542) Esta idea sobre el principio de autonomía se desarrolla durante la edad contemporánea con el reconocimiento expreso del derecho a la libertad en las grandes Declaraciones de la época. ${ }^{3}$ Así mismo las teorías del contrato social de John Locke, Hobbes, Rousseau, entre otros, influyen en la primacía del principio de autonomía, porque

2 Sara Bialostosky señala al respecto: “ Contratus para los juristas romanos, no es todo acuerdo de voluntades, sino exclusivamente aquel que da base a obligaciones sancionadas por una acción civil y por lo tanto dicho ordenamiento sólo reconoce ciertas figuras típicas contractuales (...) La voluntad de las partes no puede a discreción, ni crear los negocios jurídicos ni determinar sus elementos, Encontramos en ellos ciertos elementos que deben existir siempre , que son obra del Derecho Objetivo." Bialostosky, 2005, 133-134.

3 la Declaración de derechos de 1689 de Inglaterra, la Declaración de derechos de Virginia 1776, la Declaración de Independencia de Estados Unidos 1776, La Declaración de derechos del hombre y del ciudadano 1789, la Declaración Universal de Derechos humanos 1948, la Declaración Americana de Derechos humanos 1948. Tünnermann, 2006, p.8. 
se considera es la manifestación individual más importante de la voluntad, pues al renunciar a parte de su libertad personal para conformar un Estado, este tiene como fin reconocer y garantizar la autonomía privada como base del mismo y fuente de obligaciones jurídicas.

\section{I.2 Principio de autonomía privada como el origen de la relación contractual médico paciente}

La relación médico paciente en el ámbito jurídico es de carácter contractual, ya que antes de una intervención médica, debe existir un acuerdo entre las partes sobre los términos y condiciones de la misma. En consecuencia, existe la autonomía de la voluntad del paciente a someterse a determinado tratamiento médico, de manera libre, consciente, voluntaria e informada. ¿Qué es la autonomía privada en el ámbito contractual? es la libertad de cada parte de decidir y actuar para la satisfacción de necesidades e intereses propios, que se expresa a través del negocio y acto jurídico. El principio de autonomía de la voluntad privada es definido por varios juristas tales como:

Víctor Castrillón: "Principio de autonomía privada o libertad contractual se manifiesta en la voluntad autónomamente expresada, que determina el establecimiento de las estipulaciones que las partes se otorgan de manera libre" (Castrillón, 2008, p.1)

Al aplicar esta definición en la relación contractual médico paciente, se observa que antes de realizar una intervención médica, las partes llegan a un acuerdo en los términos y condiciones de la misma, ya que, si el paciente no está de acuerdo con los tratamientos y procedimientos médicos ofrecidos, tiene todo el derecho de no someterse al mismo, justificado en el derecho a la libertad personal, sea esta decisión tomada por motivos culturales, de credo, filosóficos o ideológicas. A su vez se infiere que el principio de autonomía privada es la capacidad de estipular los intereses propios de forma libre, no obstante, esta libertad contractual se encuentra limitada por el orden público. Al respecto Monroy Cabra señala que: 
"A través de la historia jurídica puede observarse que la iniciativa particular ha sido el motor de todas las acciones humanas (...) El orden jurídico reconoce la autonomía privada como fuente de normas jurídicas o como presupuesto y fuente generadora de relaciones jurídicas, y como actividad $y$ potestad creadoras o extintora de relaciones jurídicas entre individuo e individuo." (Monroy Cabra, 2006, p.543)

Esta opinión es compartida por varios juristas entre ellos Guillermo Ospina Fernández y Eduardo Ospina, quienes manifiestan que el principio de la autonomía es una institución natural, común de todos los pueblos reconocida por el ordenamiento jurídico que se ejerce mediante los actos o negocios jurídicos, que es el poder de los particulares de regular algunas relaciones sociales. ${ }^{4}$ No obstante, la autonomía contractual en la relación médico paciente, se encuentra limitada por: (i) Ordenamiento jurídico vigente: que establece los límites legales, así como los requisitos de validez y eficacia de los actos jurídicos. (ii) Las buenas costumbres: que son las normas morales en un contexto histórico y la realidad material de la época. (iii) La noción de orden público: límite más importante del principio de autonomía de la voluntad privada 5 .

Existen dos concepciones significativas que son: (a) Racionalista: el fin del orden público es garantizar la libertad de las transacciones particulares restringiéndose a cumplir una obligación negativa de no intervención en la libertad contractual de los particulares y sólo debe interpretar la voluntad real de los contratantes. Siendo el orden público de esta manera relegado a la voluntad de las partes. (b) Colectivista: el abuso de las libertades individuales, anteponiendo

4 "De ahí que todo ordenamiento jurídico positivo, por primitivo y rudimentario que sea el medio social a que se dirija, tiene siempre que reconocer, en alguna medida, eficacia jurídica a la iniciativa privada, permitiendo que los particulares se encarguen de arreglar entre sí parte, más o menos considerable de sus relaciones sociales, mediante actos jurídicos." (Ospina Fernández y Ospina Acosta, 2009, p. 6.)

5 Es el límite más importante, porque el desarrollo histórico del principio de autonomía privada a partir de su reconocimiento formal o positivado en el ordenamiento jurídico, demostró un abuso de este principio por parte de los particulares, que pretendieron de manera egoísta defender sus propios intereses, generalmente patrimoniales, sin considerar las necesidades sociales, ocasionando que se limite, no de forma total, el principio de autonomía privada mediante un mayor intervencionismo del Estado. 
el interés particular sobre el social, generó una tesis opuesta a la racionalista conocida como colectivista, que limita el principio de autonomía privada al bien común, interés general, función y justicia social. Se toman medidas como el intervencionismo del Estado, la economía dirigida, la integración de grupos sociales, entre otras, que busca una mejor distribución de la riqueza y elevar la calidad de vida.

En consecuencia, el principio de autonomía privada en la relación médico paciente se expresa a través de las estipulaciones contractuales de las partes sobre el servicio de salud, cuyos requisitos de validez y eficacia son limitados por el ordenamiento jurídico; ya que esta intervención médica a más de producir efectos biológicos en el paciente, lo hace en el ámbito jurídicos para ambas partes, siendo posible reclamar por la vía jurídica el incumplimiento de las estipulaciones contractuales de la prestación de servicios de salud.

\section{I.3 Principio de autonomía privada en el ámbito del bioderecho y su influencia en la relación médico paciente}

Una vez que se analizó la autonomía privada en el ámbito contractual de la relación médico paciente es indispensable analizarla desde la visión del bioderecho, porque al ser una rama del derecho cuyo objeto es regular las bases y límites de las prácticas médicas y servicios de salud, considera a la autonomía personal, como principio fundamental rector en la relación médico-paciente.

El bioderecho tiene sus propios principios que son tomados de los principios generales del derecho, sustentados en un aspecto axiológico (principios bioéticos) y son: justicia, beneficencia, no maleficencia y autonomía. El principio de autonomía desde la visión del bioderecho es definido como:

"La capacidad de autodeterminación de los pacientes y sujetos de investigación, que deben tener el derecho de decidir por sí mismos si aceptan o rechazan un determinado tratamiento o investigación, después de haber sido debidamente informados acerca de su naturaleza, objetivos, ventajas y riesgos." (Andorno, 2012, p.42)

Al analizar la definición de Andorno sobre el principio de autonomía, 
se comprende que toda persona que accede a servicios de salud tiene el derecho a decidir si se somete o no a un determinado tratamiento médico. Siendo el objetivo del principio de autonomía garantizar que el paciente y los sujetos de investigación tomen una decisión libre e informada sobre su salud. El principio de autonomía tiene una estrecha relación con la capacidad legal de las personas es por esto que se establece una protección especial para aquellas que carecen de autonomía plena como: menores de edad, discapacitados, personas con enfermedades mentales, entre otros; quienes pueden autorizar un tratamiento médico, investigación médico científica o procedimiento siempre y cuando exista una persona que sea haga responsable de tal decisión, a través de una autorización legal conforme los intereses de la persona que requiere una intervención médica. ${ }^{6}$

De este modo el principio de autonomía en la relación médico paciente es fundamental, ya que implica que un individuo es capaz de razonar y tomar decisiones, siendo consciente de los efectos de su deliberación, y negarle su libertad de actuar o no brindarle la suficiente información para actuar atenta contra su voluntad y por lo tanto su integridad como persona.

La discusión actual se centra en qué principio del bioderecho debe primar, y una las visiones bioéticas es la subjetivista, que atribuye mayor peso al principio de autonomía, pues el paciente en ejercicio de su derecho a la libertad personal y corporal debe decidir sobre su salud y esta decisión debe ser respetada, caso contrario obligarlo a someterse a un tratamiento o procedimiento médico, por más que sea necesario para su salud, sería una agresión en contra de su voluntad y dignidad humana. ${ }^{7}$

En conclusión, al analizar el principio de la autonomía privada desde el enfoque jurídico sea en el ámbito contractual o del bioderecho, se desprende existe una interrelación entre aquellos, porque ambos promueven el respeto a la autonomía o autodeterminación de la persona al momento de adoptar decisiones

6 Declaración de bioética y derechos humanos de 2005. Artículo 7.

7 Existen varios modelos de estudio de la bioética y uno de ellos es la propuesta personalista, que señala se debe individualizar los criterios de la actividad médica teniendo en cuenta la naturaleza propia del ser humano y su autorrealización, en base a su libertad de elegir. Bompiani, Bioética y ética médica en Europa Occidental, 1997, p. 224. 
libres, conscientes e informadas sobre su salud. Esta autonomía del paciente se expresa jurídicamente al aceptar o no los términos y condiciones del contrato de prestación de servicios de salud, a través de la expresión de su consentimiento informado, mismo que será analizado en el siguiente acápite.

\section{Análisis del contenido del consentimiento informado en el contrato de prestación de servicios de salud}

La necesidad de respetar la autonomía de la persona se expresa con la obligación de la solicitud del consentimiento informado, que tiene como antecedente los abusos médicos realizados, de forma principal, a partir de los experimentos médicos con presos de guerra durante la primera y segunda guerra mundial y con grupos históricamente vulnerables, por su raza, etnia, sexo y personas privadas de la libertad, entre otros.

Estos hechos tienen en común la falta de aplicación de los principios del bioderecho, entre ellos el principio de autonomía que se manifiesta con la inexistencia de voluntad de las personas al formar parte de experimentación, investigación y tratamientos médicos de manera forzada, siendo una clara violación de sus derechos tales como: libertad personal, integridad, vida privada, entre otros.

El derecho a la libertad personal es reconocido en varios instrumentos internacionales como la Carta Internacional de Derechos Humanos de la ONU, la Declaración Americana de Derechos Humanos y el Convenio Americano de Derechos Humanos. Estos instrumentos internacionales definen al derecho a la libertad personal como aquel que goza toda persona, que se ejerce a través del uso de la razón y conciencia para entender y obrar de forma libre. La libertad general es

"La libertad para actuar y decidir libremente el propio comportamiento en todos los casos, sin obstáculos, barreras o coacciones de los poderes públicos, de otros grupos sociales y de los particulares." (Barba-Martínez, 2018, p.140) 
En todos los casos de procedimientos, tratamientos e investigación científica con seres humanos el principio de autonomía privada y el derecho a la libertad se manifiestan con el consentimiento informado, que debe ser solicitado por el médico una vez que brindó la información detallada sobre los mismos. De esta manera se garantiza a los pacientes el ejercicio del derecho a la libertad personal de elegir de forma voluntaria, libre e informada sobre su salud personal, mientras que, a los médicos, la garantía al ejercicio del derecho a la libertad científica $^{8}$; que basada en la experiencia y conocimiento técnico les permite decidir qué proceso y tratamiento médico es el más adecuado para el paciente, de conformidad con el diagnóstico, cuadro clínico y necesidades de cada uno.

\section{II.1 Análisis del consentimiento informado desde el ámbito contractual, requisitos y características}

Desde la visión contractual, es considerado un elemento esencial del contrato de prestación de servicios médicos, en consecuencia, sin su existencia no sería válido ni eficaz el contrato. El objeto del contrato de prestación de servicios médicos es brindar atención médica, para determinar, el diagnóstico, procedimiento y tratamiento de un paciente en base a una evaluación previa de su salud, el cuadro clínico y necesidades propias de cada caso.

Las Buenas Prácticas Clínicas (BPC) de 1993 de la OMS establecen un concepto, aceptado de manera general, sobre el consentimiento informado que es la expresión de voluntad de la persona que se quiera someter a un diagnóstico, tratamiento o cualquier procedimiento médico o de investigación científica, para lo cual debe haber comprendido la información que se le dio sobre los objetos, riesgos, beneficios, derechos y responsabilidades. En caso de tratamiento médico dependerá del alcance y la incidencia de este para determinar si el consentimiento debe ser por escrito o sólo de manera verbal, por ejemplo, al realizar un

8 El Alto Comisionado para los Derechos Humanos de la ONU (ACNUDH) expresa que inicialmente se reconoció a la libertad científica dentro del derecho a la libertad de expresión en el artículo 19 numeral 2 de la DUDH aunque años más tarde se considera a la libertad de investigación como un derecho independiente de la libertad de expresión al reconocerlo en el PIDESC Art. Art. $15 \mathrm{~N}^{\circ} 3$ que dice "Los Estados Partes en el presente Pacto se comprometen a respetar la indispensable libertad para la investigación científica y para la actividad creadora." Esta separación se debe al carácter evolutivo y dinámico de los derechos humanos. 
examen médico de rutina el consentimiento informado puede ser verbal, pero en procedimiento, tratamientos médicos e investigación médico-científica más compleja debe ser siempre por escrito. (OMS, PBC, 1993, p.15-16) ${ }^{9}$

Las pautas mencionadas de la OMS crearon un formulario, modelo de consentimiento informado que establece los requisitos mínimos del mismo y son: (i)Voluntad: es el ánimo o la capacidad de decidir de forma libre sin determinismo alguno o vicios del consentimiento sea error, fuerza o dolo. (ii) Capacidad legal: se refiere a la capacidad civil, es decir que sea mayor de edad, pero en caso de menores de edad debe ser otorgada por la persona responsable, y para las personas con discapacidades física o mentales, se les reconoce el principio de autonomía siempre y cuando su discapacidad les permita de forma libre y razonada elegir ${ }^{10}$ caso contrario será otorgado por la persona responsable. (iii) Información: vinculante al tratamiento, procedimiento o investigación médico-científica, que debe ser clara, precisa, previa, en el idioma de la persona(s) que otorga(n) su consentimiento, con un lenguaje general y no técnico y que proporcione toda la información necesaria sobre el procedimiento a realizar, sus efectos, riesgos, beneficios, alternativas, derechos y responsabilidades. (iv) Comprensión: por parte del paciente y sujetos de experimentación médico-científica, para así deliberar acerca de las alternativas y elegir la más conveniente. (OMS, PBC,1993, p.16).

Al analizar los requisitos del consentimiento informado se comprende que estos son los que dan validez y eficacia legal al mismo, ya que es un documento con efecto jurídicos, cuya finalidad es servir de prueba en caso de un conflicto entre las partes. A continuación, se señala a criterio propio con las características básicas del consentimiento informado que de forma general son:

i. Expreso. Manifiesto de manera evidente por quien se somete al tratamiento médico o a la investigación científica. Las excepciones al consentimiento

9 Estas pautas son seguidas por organismos internacionales como la Organización Panamericana de la Salud (OPS), Asociación médica mundial (AMM), entre otras organizaciones.

10 "Exigirán a los profesionales de la salud que presten a las personas con discapacidad atención de la misma calidad que a las demás personas sobre la base de un consentimiento libre e informado, entre otras formas" Convención sobre los derechos de las personas con discapacidad, ONU, 2006, artículo 25 literal d. 
informado son: a) Si el individuo es considerado un riesgo para la sociedad, porque posee alguna enfermedad mental o física que afecte a la sociedad o a la salud pública. b) Riesgo inmediato para la integridad física o psíquica, que aplica al caso de las emergencias médicas. c) Incapacidad legalmente reconocida, para lo cual se necesita el consentimiento del representante legal. d) Convicciones religiosas o ideológicas de la persona, quien puede reusarse a que se aplique el tratamiento médico, un ejemplo es el caso de los testigos de jehová y los mormones. (Pérez y Cantora, 2006, p.63)

ii. Escrito. El consentimiento informado es un documento legal, que constituye prueba, debiendo constar por escrito para que a diferencia de un consentimiento verbal no exista duda sobre el contenido. Todo consentimiento informado debe ser redactado en el idioma del paciente con un lenguaje común y no técnico para su comprensión y debe contener la información necesaria sobre el centro médico y la designación del médico encargado, fecha de suscripción del consentimiento, información sobre la evaluación previa y el diagnóstico emitido por un médico profesional, información sobre el tratamiento (objeto, procedimiento, beneficios, riesgos, complicaciones), derechos y responsabilidades del paciente, obligaciones del centro médico y garantía de confidencialidad sobre la información.

iii. Previo. Antes de aceptar el tratamiento médico o participar en la investigación, de esta forma la persona analizar la información y delibera sobre su decisión.

iv. Continuo. La información debe ser proporcionada de forma constante para la modificación del consentimiento conforme el avance del tratamiento y el pronóstico, es deber del médico informar sobre nuevos riesgos, efectos secundarios y alternativas al tratamiento, que se vayan suscitando durante el tratamiento o procedimiento. ${ }^{11}$

11 Al respecto la tratadista Sonia Merlyn menciona: "el consentimiento informado no se agota en la primera entrevista, sino debe continuar a lo largo de las diversas etapas del tratamiento". Merlyn, 2006, p.94. Se fundamenta en que la investigación o tratamiento es un proceso continuo y los encargados están en la obligación de controlar en forma constante a las personas involucradas para verificar si existe algún cambio sustancial, que deba ser informado y actualizar el documento del consentimiento informado o reiniciar el proceso con un nuevo 
v. Revocable. En cualquier momento por parte del paciente sin que exista ningún tipo de sanción o responsabilidad civil o penal, aunque es recomendable hacerlo con anticipación al tratamiento o investigación para proteger la integridad personal y se debe notificar de forma escrita.

\section{II.2 Principio de consentimiento informado en el bioderecho}

Se considera que el principio de consentimiento informado es un principio derivado del principio de autonomía, que ha sido reconocido en diferentes instrumentos internacionales vinculantes al bioderecho como: la declaración de bioética y derechos humanos de 2005 (Art. 6) y en la Declaración de Helsinki del 2013 (artículos 25-31). Si bien únicamente la Declaración de bioética y DD.HH de 2005 refleja un compromiso vinculante a los Estados miembros de la ONU que la suscribieron y ratificaron, la Declaración de Helsinki en la práctica es desde 1964 una guía para las políticas públicas y la creación de Leyes sobre bioderecho, ya que en ambos instrumentos señala la obligación de los médicos de solicitar el consentimiento informado, para tratamientos, procedimientos e investigación médico-científica, debe ser otorgado de manera voluntaria y en caso de ser necesario se puede consultar a los familiares o líderes comunitarios; al respecto la Declaración de Bioética señala:

"En los casos correspondientes a investigaciones llevadas a cabo en un grupo de personas o una comunidad, se podrá pedir además el acuerdo de los representantes legales del grupo o la comunidad en cuestión. El acuerdo colectivo de una comunidad o el consentimiento de un dirigente comunitario u otra autoridad no deberían sustituir en caso alguno el consentimiento informado de una persona." (Declaración de bioética y Derechos Humanos, 2005, Art. 6.3)

Al analizar la cita se infiere que siempre será más importante el consentimiento informado individual de una persona, sobre el de su comunidad, lo que demuestra la importancia de la autonomía propia, ya que caso contrario sería una directa violación a su derecho a la libertad personal.

documento que incluya la nueva información. Pérez y Cantora, ץ .. `, p.65. 
Asimismo, se debe mencionar que la Declaración de Helsinki al ser revisada periódicamente busca la actualización de las pautas generales sobre el consentimiento informado, es así como en una de sus revisiones introdujo la obligación de los médicos de solicitar el consentimiento informado incluso si se utiliza datos humanos contenidos en biobancos o depósitos similares, al respecto el mencionado instrumento indica:

"Para la investigación médica en que se utilice material o datos humanos identificables, como la investigación sobre material o datos contenidos en biobancos o depósitos similares, el médico debe pedir el consentimiento informado para la recolección, almacenamiento y reutilización.” (Declaración de Helsinki, revisada al 2013, párr. 32)

En consecuencia, tanto en la Declaración de Bioética y DD.HH de 2005 promulgada por la UNESCO tanto como en la Declaración de Helsinki revisada al 2013 por la Asociación Médica Mundial (AMM) se reconoce al consentimiento informado como la expresión máxima de voluntad del paciente o sujeto de investigación médico científica siempre en base a información previa, siendo vital su solicitud caso contrario se actuaría contra la voluntad del individuo, lo que atenta contra su derecho a la vida, integridad, libertad y salud. No obstante, en la práctica se evidencia que existen diferencias entre la opinión médica y la del paciente sobre cuál tratamiento o procedimiento es el más adecuado, generando inconvenientes como ejemplo:

"En la mayoría de las ocasiones, se carga al paciente con decisiones que le superan por falta de formación e información necesaria. Con ello se le priva del beneficioso abandono en la confianza del profesional, cuyos efectos terapéuticos en el transcurso de la enfermedad pueden ser muy favorables." (Vila de Coro, 2010, pp. 275-276)

La opinión de Vila de Coro demuestra, una vez más, la necesidad de establecer qué principios bioéticos priman sobre otros, dependiendo de cada caso, sin embargo, es una discusión en la que aún no hay consenso. 


\section{Consentimiento informado garantía del ejercicio del derecho a la salud}

En los acápites anteriores se analizó utilizando el método deductivo y exegético, el principio de autonomía desde el derecho y su influencia en la relación médico paciente. Sea en el ámbito contractual o del bioderecho ambos enfatizan en la importancia del principio de autonomía como la máxima expresión de voluntad de un individuo al adoptar decisiones y actuar, mismas que generalmente tienen efectos jurídicos. Asimismo, se demostró que la relación médico paciente es contractual y requiere de la expresión de la voluntad o ejercicio de la autonomía del paciente, a través de la manifestación expresa del consentimiento informado, elemento esencial contenido en el contrato de prestación de servicios de salud, que debe cumplir con requisitos legales para su validez y eficacia. También se debe recalcar que desde el ámbito del bioderecho el principio de autonomía rige la relación entre médico paciente, con el objetivo de garantizar el ejercicio de derechos tales como: libertad, integridad personal, vida privada, entre otros.

No obstante, a pesar que el principio de autonomía es fundamental en la teoría el derecho para la toma de decisiones y el actuar de los individuos, en la práctica aquel principio no es respetado, por lo tanto, en el presente acápite utilizando el método de derecho comparado y de informe del caso se analizará dos sentencias de tribunales regionales en los que se evidencia la desnaturalización y descontextualización del principio de autonomía y en consecuencia la violación al consentimiento informado, estos casos son: i) Caso internacional de Evans vs. Reino Unido cuya sentencia fue emitida por el Tribunal Europeo de Derechos Humanos en marzo de 2006; y ii) Caso Regional Ximenes Lopes vs. Brasil sentencia de la CorteIDH de julio de 2006.

\section{III.1 Regional: Caso Ximenes Lopes vs. Brasil sentencia de la Corte IDH}

Hechos jurídicamente relevantes: Damião Ximenes durante su juventud desarrolló una discapacidad mental de origen orgánico, proveniente de alteraciones en el funcionamiento de su cerebro. El 1 de octubre de 1999 fue internado en la 
casa reposo Guararapes, centro privado, para recibir tratamiento psiquiátrico. Al momento de ser admitido como paciente gozaba de perfecto estado físico de salud y no presentaba señales de lesiones corporales externas ni conducta agresiva. El 3 de octubre de 1999 Damião Ximenes tuvo una crisis de agresividad y estaba desorientado, por lo que fue dominado y retirado a la fuerza por un auxiliar de enfermería y por otros dos pacientes. El 4 de octubre de 1999, la madre de Damião Ximenes fue a visitarlo a la Casa de Reposo Guararapes y lo encontró con lesiones corporales (sangrando y hematomas), con las manos amarradas hacia atrás, con dificultad para respirar, agonizante, gritando y pidiendo auxilio a la policía. El señor Ximenes Lopes seguía sometido a la contención física que le había sido aplicada desde la noche anterior. (Ximenes Lopes, CorteIDH, 2006, párrs.133-136). Damião Ximenes falleció el mismo día, aproximadamente dos horas después de haber sido medicado por el director clínico del hospital, y sin ser asistido por médico alguno en el momento de su muerte. Un día después se realizó la autopsia cuyo informe concluyó que la muerte del Sr. Ximenes Lopes era indeterminada. En julio de 2000 se cerró definitivamente la Casa de Reposo Guararapes.

Historia procesal: La familia del señor Ximenes Lopes presentó el día de su muerte (4 de octubre de 1999) una denuncia ante la comisaría de policía, que no inició una investigación. Motivo por el cual en el 2000 denunciaron ante la Comisión de Derecho Humanos de Brasil, así mismo iniciaron acciones civiles y penales, pero hasta la notificación formal de la sentencia del proceso por la CorteIDH no hubo una sentencia de los recursos internos, en consecuencia, se considera que hubo una demora injustificada. (Ximenes Lopes, CorteIDH, 2006, párr. 203)

Pretensión y cuestión de derecho que se busca resolver: La Comisión Interamericana de Derechos Humanos en conjunto con la madre del señor Ximenes Lopes presentó el 1 de octubre de 2004 la demanda ante la Corte Interamericana de Derechos Humanos (CorteIDH) cuya pretensión fue que se declare la violación del Estado de Brasil de los derechos consagrados en la Convención Interamericana de Derechos Humanos ( La Convención) en los artículos: Art.4 derecho a la vida, Art.5 derecho a la integridad personal, Art. 8 derecho a las 
garantías judiciales, Art. 25 derecho a la protección judicial en relación con la obligación para los Estados miembros de respetar los derechos reconocidos en La Convención establecida en el Art. 1.1. La cuestión de derecho que resolvió la CorteIDH es si se violaron los derechos mencionados y si se respetó o no el ejercicio de la autonomía a través de la solicitud del consentimiento informado del señor Lopes. (Ximenes Lopes, CorteIDH, 2006, párr. 20)

Análisis jurídico y Resolución: Después de analizar los instrumentos vinculantes como Convención Americana de Derechos Humanos de 1969, Convención Interamericana para la Eliminación de Todas las Formas de Discriminación, Principios para la Protección de los Enfermos Mentales y el Mejoramiento de la Atención de Salud Mental ONU de 1991 entre los más principales. La CorteIDH determinó: i) El Estado brasilero vulneró el derecho a la vida y a la integridad personal (artículo 4 y 5 de la Convención) del señor Ximenes, porque no ejerció la debida fiscalización de la Casa de Reposo Guararapes, que no cumplió con los requisitos para prestar servicios de salud psiquiátrica, al no contar con las instalaciones, personal profesional y la administración adecuada. (Ximenes Lopes, CorteIDH, 2006, párr.142) Sometiéndolo a un trato cruel, inhumano y degradante como fue la contención o sujeción física aplicada al señor Ximenes Lopes, que no tomó en cuenta los parámetros internacionales sobre la materia, pues se lo hizo sin un fundamento válido y bajo condiciones inhumanas al maniatarlo y golpearlo hasta fallecer. (Ximenes Lopes, CorteIDH, 2006, párr.146) Además, la falta de una investigación seria y sanción a los responsables por la muerte del señor Ximenes Lopes, constituye una violación por parte del Estado a su obligación de garantizar el derecho a la vida. ii) La Corte considera que la discapacidad mental no debe ser entendida como una imposibilidad para auto determinarse, y debe aplicarse la presunción de que las personas que padecen de ese tipo de discapacidades son competentes de expresar su voluntad, la que debe ser respetada por el personal médico y las autoridades. Una vez comprobada la imposibilidad para consentir, corresponderá a sus familiares, representantes legales o a la autoridad competente, emitir el consentimiento en relación con el tratamiento a ser empleado. (Ximenes Lopes, CorteIDH, 2006, párr.130) 


\section{III.2 Internacional: Caso Evans vs. Reino Unido Tribunal Europeo}

Hechos jurídicamente relevantes: El Sr. J y la Srta. Evans estuvieron casados desde 1995, en julio de 2000 iniciaron un tratamiento de reproducción humana asistida (RHA), debido a que habían intentado concebir durante varios años, pero no lo lograron, ya que la señora Evans tenía tumores pre-cancerígenos en sus ovarios y debían ser removidos. No obstante, a través de técnicas de reproducción humana asistida (TRA) como: i) la extracción de óvulos antes de la remoción de los ovarios. ii) Uso de los óvulos de la señorita Evans y el esperma del señor J para ser mezclados en el laboratorio utilizado la TRA de fertilización in vitro (FIV)y (iii) Criopreservación de los embriones obtenidos, podría la Sra. Evans concebir. El Centro les indica que para realizar el procedimiento conforme la ley de RHA de 1990 (HFEA) deben firmar el consentimiento informado, de forma individual, el cual podrá ser revocado hasta antes de la transferencia del embrión(es), que se obtenga(n) para la extracción y mezcla de sus gametos. El señor J y la señora Evans suscribieron el consentimiento informado para la criopreservación de los embriones obtenidos. El 26 de noviembre del año 2000 se realizó la cirugía de remoción de ovarios a la Srta. Evans y se le indicó que debido a los efectos de la operación debía esperar dos años para proceder a la transferencia de los embriones criopreservados. En mayo de 2002 la pareja decidió divorciarse y en julio de 2002 el Sr. J notificó por escrito a El Centro su voluntad de revocar el consentimiento informado, por lo que los embriones de conformidad con la ley de Reino Unido HFEA de 1990 debían ser descartados. (Evans v. Reino Unido, 2006, párrs. 9, 12,13)

Historia procesal: La Srta. Evans presentó una acción ante la Alta Corte de Reino Unido solicitando una orden judicial de restauración del consentimiento de su ex pareja. El juez emitió sentencia en octubre de 2003 a favor de su ex pareja, manifestando que obligarlo a restaurar su consentimiento sería una violación grave al principio de autonomía privada, porque se estaría atentando contra su voluntad y en el supuesto que se le obligue tendría efectos en: i) Su vida privada al ser considerado el padre biológico de los posibles hijos y ii) Efectos patrimoniales 
derivados de la paternidad, pues tendría la obligación de cubrir económicamente con las necesidades de alimentos, vestimenta, hogar, educación, entre otras, de los posibles hijos. También se estaría violando lo dispuesto en la Ley que regula sobre la materia, pues permite revocar el consentimiento informado hasta antes de la transferencia de embriones. Esta sentencia fue apelada por la señorita Evans, sin embargo, fue favorable para el Señor J, ya que la Corte manifestó que la intención de los legisladores era garantizar el ejercicio del principio de autonomía a través del consentimiento informado, para que las personas decidan de manera libre sobre su vida privada. Así mismo la Corte señalo que el consentimiento informado es para ambas partes, ya que ninguno puede obligar al otro a ser padre o madre, puesto que para ambos acarrea la responsabilidad de por vida de cuidado y crianza de el/los posibles hijos. En consecuencia, para la transferencia de embriones es necesario contar con el consentimiento bilateral de ambas partes, en el caso de parejas estén o no unidas por matrimonio. (Evans v. Reino Unido, 2006, párrs. 15,16 y 19)

Pretensión y cuestión de derecho que se busca resolver: La Srta. Evans decidió iniciar un proceso ante el Tribunal Europeo de Derechos Humanos (TEDH) con la pretensión que se restaure el consentimiento informado de su ex pareja, alegando la violación de sus derechos reconocidos en el Convenio Europeo de Derechos humanos que son: respeto de la vida privada y familiar (Art.8), prohibición de discriminación (Art.14) y el derecho a la vida (Art. 2). La cuestión de derecho que busca resolver el Tribunal es determinar si hubo o no la violación de los derechos mencionados y si es posible obligar a un tercero a restaurar su consentimiento informado una vez revocado.

Análisis jurídico y Resolución: Después de analizar los instrumentos internacionales vinculantes tales como: El Convenio Europeo de Derechos Humanos (El Convenio), el Convenio Europeo de Derechos Humanos y Biomedicina ( CEDHB) y la Declaración de Derechos Humanos y Bioética de 2005, el TEDH concluye que: (i) No existe la violación del derecho a la vida en relación al embrión ( Art. 2 del Convenio), debido a que no hay un acuerdo sobre el inicio de la vida humana en el Consejo Europeo, en consecuencia se dejó a discreción de cada país miembro determinar cuándo inicia la vida humana, 
para Reino Unido el embrión pre-implantatorio no constituye vida humana. por lo tanto, no se ha violado el derecho a la vida. (Evans v. Reino Unido, 2006, párrs.46-47) (ii) El TEDH señala que el derecho a la vida privada y familiar en el presente caso afecta a ambas partes, puesto que la vida privada abarca varios ámbitos como el respeto al principio de autonomía que permite a las personas tomar decisiones libres y auto determinarse como lo desee, incluye el derecho decidir sobre su vida familiar, con quién formar una familia y si procrear o no. El Estado debe garantizar el consentimiento bilateral hasta el momento de la implantación de los embriones, si una de las partes revoca su consentimiento antes de la implantación es válido, porque caso contrario las repercusiones de obligar a la persona a ser padre o madre al forzarle a mantener el consentimiento informado sería una interferencia directa del Estado sobre su autonomía y su vida privada. La injerencia del consentimiento informado es para ambas partes, porque los efectos de dicho consentimiento es la posible existencia de vida humana y la obligación de cuidado y crianza de aquella, que va más allá de una obligación financiera, puesto que implica aspectos éticos y personales para cada individuo. Por las razones expuestas el TEDH considera que Reino Unido no viola el Art.8 de El Convenio, porque la intervención es mínima y justificada en la razón de garantizar el ejercicio de los derechos y libertades de las personas que acceden a los servicios de RHA al prever la necesidad del consentimiento bilateral, en todo momento del proceso y la posibilidad de revocar el consentimiento hasta el momento de la implantación. (Evans v. Reino Unido, 2006, párrs. 66-69) (iii) En cuanto a la no aplicación del Art. 14 del Convenio la Srta. Evans estableció que ha sido discriminada en comparación con las mujeres que pueden concebir de forma natural, porque El Estado no prevé la revocatoria del consentimiento en los casos de concepción natural, al respecto el TEDH señala que no existe discriminación, ya que en la concepción natural como en la artificial, es necesario contar con el consentimiento de la pareja; y la única diferencia entre ambas, es que la fertilización en la concepción artificial es extracorpórea, entonces al igual que en la concepción natural es indispensable contar con el consentimiento de ambas partes. (Evans v. Reino Unido, 2006, párrs. 73-74) (iv) El TEDH manifiesta que la Srta. Evans a pesar de no estar autorizada para hacer uso de los embriones mezclados con sus óvulos y el esperma del Sr. J no se elimina la posibilidad de 
concebir, ya que existen alternativas como la solicitud de donación de embriones pre-implantatorios ante El Centro.

Al analizar en conjunto estos dos casos se infiere que el criterio de ambos Tribunales es considerar al principio de autonomía como fundamental para el ejercicio de derechos tales como: libertad, vida privada, integridad personal y salud. En el ámbito de la relación médico paciente es indispensable el respeto al principio de autonomía, porque el paciente demuestra su voluntad libre, consciente e informada de realizarse, continuar e incluso finalizar un tratamiento o procedimiento médico. Dicha voluntad se ejerce a través del consentimiento informado, que es un requisito esencial del contrato de prestación de servicios médicos y una garantía del ejercicio del derecho a la salud. En estos casos se evidencia que el consentimiento informado puede ser manifestado de forma positiva al aceptar el tratamiento o de manera negativa al rechazarlo o revocarlo. Los conflictos se dan cuando no se solicita el consentimiento informado tal como sucede en el caso Ximenes Lopes o cuando no se respeta la decisión de revocar el mismo y se pretende obligar a restáuralo, tal como se evidencia en el caso Evans vs. Reino Unido, porque se vulnera el derecho a la salud, libertad, vida privada e integridad al no aplicar el principio de autonomía, que es determinante para el libre desarrollo de sus vidas.

\section{Conclusiones}

1. El principio de autonomía en la teoría general del derecho, sea considerado desde la noción contractual o del bioderecho es la libertad personal de decidir de forma libre, voluntaria e informada, cuya mayor expresión es el negocio y acto jurídico. Por lo tanto, el ordenamiento jurídico establece el cumplimiento de requisitos mínimos para que el acto jurídico sea válido y eficaz, sin que esto implique la interferencia sobre la autonomía y voluntad personal. No obstante, el principio de autonomía no es absoluto, porque tal como se analizó en el presente ensayo está limitado por: el orden público, derechos y libertades de otros, salud, seguridad pública y las buenas costumbres, pero estos límites no deben 
desconocer la autonomía de los individuos reconocida por el Estado.

2. En la relación médico paciente que es de naturaleza contractual el principio de autonomía es fundamental, ya que es la expresión de voluntad del paciente de aceptar, rechazar o revocar un tratamiento o procedimiento médico. Asimismo, el principio de autonomía, desde ámbito del bioderecho, en la práctica entra en conflicto con otros principios bioéticos como el de beneficencia y no maleficencia, debido a que la idea de lo que es beneficioso para el paciente puede diferir con la del médico, por ejemplo, cuando el paciente quiere continuar, modificar o suspender un tratamiento contra el criterio médico, de conformidad a lo sucedido en el caso Evans vs. Reino Unido. Se considera que, dependiendo de las circunstancias de cada caso, en algunos momentos primara el principio de autonomía como en los casos analizados en el presente ensayo, ya que de manera general es obligación negativa la no intervención por parte del Estado ni de terceros sobre la autonomía privada. Sin que esto signifique no permitir actuar al médico conforme el bienestar el paciente, las reglas de la buena práctica médica y ejercer su derecho a la libertad científica, a través de un diagnóstico, conocimientos médicos técnicos y su experiencia para determinar el mejor tratamiento y procedimiento médico para su paciente.

3. El consentimiento informado es un elemento esencial del contrato de prestación de servicios de salud, por lo tanto, debe cumplir con ciertos requisitos mínimos como: la información clara precisa y suficiente, comprensión por parte del individuo de la información, la voluntariedad que prevé la no existencia de vicios del consentimiento (error, fuerza o dolo), constancia por escrito o por algún medio documentado, ya que en caso de conflicto jurídico será prueba e incluso si no cumpliere con los requisitos mínimos se afectará a la validez y eficacia del consentimiento informado siendo nulo.

4. El consentimiento informado es una garantía del ejercicio del derecho a la salud, que abarca dos aspectos: (1) La libertad o autonomía de la persona de decidir sobre su salud, cuya declaración es el consentimiento informado, y (2) El acceso a servicios de salud que cumplan con parámetros mínimos de calidad, disponibilidad, accesibilidad y adaptabilidad, que influyen en la decisión de las 
personas al aceptar o no un servicio de salud. En consecuencia, para ejercer el derecho a la salud es indispensable el consentimiento informado de la persona, que se manifiesta de forma positiva al aceptarlo o modificarlo, y negativa al rechazarlo o revocarlo, siendo, cualquiera de las opciones válidas, siempre y cuando se considere las disposiciones legales que regulan el consentimiento informado.

\section{Bibliografía}

Andorno, R. (2012) Bioética y dignidad de las personas. Madrid: Tecnos. Bialostosky, S. (2005) Panorama del derecho romano. México D.F.: Porrúa.

Bompiani, A. (1997) Bioética y ética médica en Europa Occidental. Trieste, Italia: Scientific Press.

Cabanellas, G. (2008) Diccionario jurídico elemental. Buenos Aires: Heliasta.

Cabra, M. (2008) Introducción al Derecho. Bogotá: Temis.

Castrillón, V. (2008) "La libertad contractual". Revista Facultad de derecho de México, julio-diciembre, LVIII, No. 250, 2008. Recuperado de http://www.derecho.unam.mx/revista/revista_250/ articulo09-250.html.

CorteIDH. Caso Ximenes Lopes vs. Brasil. Sentencia del 4 de julio de 2006. Serie No. 149.

Convenio Europeo de derechos humanos del Consejo de Europa reformado al 2010.

Merlyn, S. (2006) Derecho y reproducción asistida. Quito: Cevallos.

Opina, F. y Ospina, E. (2009) Teoría general del contrato y del negocio jurídico. Bogotá: Temis.

Peces- Barba Martínez, G. (2015) Lecciones de derechos fundamentales. Madrid: Dykinson.

Pérez, M. y Cantora, C. "El consentimiento informado como garantía constitucional desde la perspectiva del derecho mexicano". Revista 
DERECHO GLOBAL. ESTUDIOS SOBRE DERECHO Y JUSTICIA

de Derecho Privado: nueva época, Vol. 5 No. 15, 2006, pp. 59-87. TEDH. Caso Evans vs. Reino Unido. Sentencia de 10 de abril de 2007. Tünnermann, C. (2006) Los Derechos Humanos evolución histórica y reto educativo. 3era. ed. Unesco.

Vila de Coro, M. (2010) La vida humana en la encrucijada: pensar la bioética. Madrid: ediciones encuentro. 